\title{
Respon Dinamis Kurs terhadap Tingkat Bunga di Indonesia
}

\section{Dynamic Response of Exchange Rate to Interest Rate in Indonesia}

\author{
Nanda Rahmi ${ }^{1)}$, Kamal Fachrurrozi ${ }^{2)}$ \\ ${ }^{1,2)}$ Fakultas Ekonomi dan Bisnis, Universitas Syiah Kuala, Banda Aceh \\ e-mail korespondensi:nanda_rahmi84@unsyiah.ac.id
}

\begin{tabular}{|c|c|}
\hline Info Artikel & Abstrak \\
\hline $\begin{array}{l}\text { Riwayat Artikel: } \\
\text { Diterima: } 19 \text { Februari } 2020 \\
\text { Disetujui: } 21 \text { September } 2020 \\
\text { Dipublikasikan: Januari } 2021\end{array}$ & $\begin{array}{l}\text { Tujuan penelitian ini adalah untuk menganalisis respon dinamis kurs terhadap } \\
\text { tingkat bunga di Indonesia. Data tahun dari } 2002 \text { hingga } 2018 \text { digunakan dalam } \\
\text { penelitian ini dengan model analisis autoregresif untuk mengetahui pengaruh } \\
\text { dinamis. Hasil penelitian menunjukkan bahwa kurs sangat responsif terhadap }\end{array}$ \\
\hline $\begin{array}{l}\text { Nomor DOI } \\
\text { 10.33059/jseb.v12i1.2107 } \\
\text { Cara Mensitasi : } \\
\text { Rahmi, N., \& Fachrurrozi, K. } \\
\text { (2021). Respon dinamis kurs } \\
\text { terhadap tingkat bunga di } \\
\text { Indonesia. Jurnal Samudra } \\
\text { Ekonomi dan Bisnis, 12(1), } \\
\text { 117-129. doi: 10.33059/jseb. } \\
\text { v12i1.2107. }\end{array}$ & $\begin{array}{l}\text { tingkat bunga baik dalam jangka pendek maupun jangka panjang. Pengaruh } \\
\text { tingkat bunga dalam jangka panjang lebih besar (elastis) dibandingkan dengan } \\
\text { jangka pendek. Otoritas moneter perlu memperkuat findamental ekonomi } \\
\text { domestik sehingga peran tingkat bunga lebih efektif untuk menstabilkan } \\
\text { fluktuasi kurs. } \\
\text { Kata Kunci: Nilai Tukar, Tingkat Suku Bunga, Model Dinamis, Indonesia. }\end{array}$ \\
\hline
\end{tabular}

\begin{tabular}{|c|c|}
\hline Article Info & Abstract \\
\hline $\begin{array}{l}\text { Article History: } \\
\text { Received: } 19 \text { February } 2020 \\
\text { Accepted: } 21 \text { September } 2020 \\
\text { Published: January } 2021\end{array}$ & $\begin{array}{l}\text { This study is to analyze the dynamic response of exchange rate to interest rate } \\
\text { in Indonesia. Yearly data form } 2002 \text { to } 2018 \text { are used in this study and } \\
\text { autoregressive model is utilized to capture dynamic response. The results show } \\
\text { that the exchange rate has negative and significant response to interest rate. }\end{array}$ \\
\hline $\begin{array}{l}\text { DOI Number: } \\
\text { 10.33059/jseb.v12i1.2107 } \\
\text { How to cite : } \\
\text { Rahmi, N., \& Fachrurrozi, K. } \\
\text { (2021). Respon dinamis kurs } \\
\text { terhadap tingkat bunga di } \\
\text { Indonesia. Jurnal Samudra } \\
\text { Ekonomi dan Bisnis, 12(1), } \\
\text { 117-129. doi: 10.33059/jseb. } \\
\text { v12i1.2107. }\end{array}$ & $\begin{array}{l}\text { Furthermore, the effects of interest rate on exchange rate is higher in longrun } \\
\text { than short-run. It is suggested to monetary authority to strength the domestic } \\
\text { fundamental to achieve more effective of interest rate to stabilize the exchange } \\
\text { rate fluctuations. } \\
\text { Keywords: Exchange Rate, Interest Rate, Dynamic Models, Indonesia. }\end{array}$ \\
\hline
\end{tabular}




\section{PENDAHULUAN}

Salah satu target kebijakan ekonomi suatu negara yang menganut sistem perekonomian terbuka adalah stabilitas sektor luar negeri. Stabilitas sektor luar negeri ini sangat penting untuk menjamin kegiatan ekspor dan impor (Todaro, 2000). Demi menjamin kelancaran dari transaksi dalam kegiatan ekspor dan impor tersebut maka uang ditetapkan sebagai alat pembayaran. Mata uang yang digunakan setiap negara berbeda dan juga memiliki perbedaan nilai tukarnya, dan perbedaan itu biasa disebut dengan kurs, dimana nilai kurs sendiri tidak selalu tetap atau berfluktuasi. Fluktuasi kurs pasti terjadi namun tingkat depresiasi dan apresiasi yang tidak terlalu besar perlu dipertahankan agar eksportir dan importir mampu melakukan penyesuaian terhadap fluktuasi kurs tersebut.

Fluktuasi kurs ini tidak terlepas dari sistem perekonomian yang dianut negara. Dalam hal ini, Indonesia misalnya, sebagai negara yang menganut sistem perekonomian terbuka kecil (small open economy), dimana derajat partisipasinya dalam perdagangan internasional masih sangat kecil. Dengan demikian, perekonomian Indonesia sangat terpengaruh dengan kondisi perekonomian global yang tercermin dari fluktuasi kurs.
Fluktuasi kurs ini bisa disebabkan oleh faktor eksternal yaitu perekonomian mitra dagang atau kondisi ekonomi global, dengan faktor internal yaitu kondisi perekonomian dalam negeri. Kondisi internal relatif lebih mudah untuk diawasi oleh pemerintah dengan otoritas pengambil kebijakan lainnya di bidang moneter. Namun, kondisi eksternal sangat mustahil mampu dilakukan pemerintah karena fluktuasi kurs bersifat eksogen.

Gambar 1 memperlihatkan fluktuasi kurs rupiah terhadap dolar Amerika yang sebagian mengalami apresiasi, tetapi lebih banyak mengalami depresiasi. Akhir tahun 2018 rupiah mengalami depresiasi, hal ini biasanya terjadi karena sebagian besar perusahaan melakukan pembayaran hutang yang telah jatuh tempo yang berakibat pada peningkatan permintaan dolar. Saat rupiah mengalami depresiasi, diikuti peningkatan ekspor sehingga pasokan dolar meningkat, dan rupiah mengalami apresiasi. Pada bulan Februari 2019, apresiasi rupiah biasanya akan diikuti oleh peningkatan impor yang berakibat pada penurunan cadangan dolar di dalam negeri. Keadaan ini berakibat pada depresiasi rupiah yang terus meningkat sejak April 2019, dan siklus fluktuasi ini akan terus terjadi.

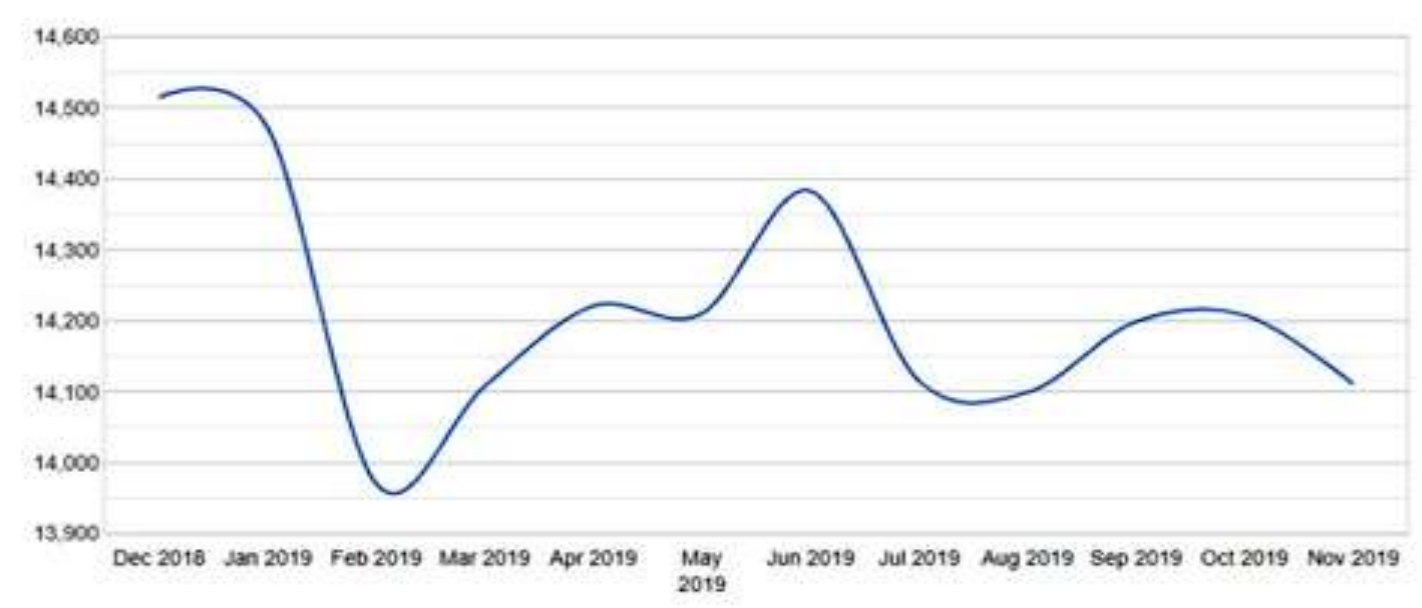

Gambar 1. Tren Kurs Rupiah terhadap Dollar Periode Desember 2018 - November 2019 Sumber: Anonim (2019). 
Siklus atau tren fluktuasi kurs ini akan berpengaruh terhadap ekspor-impor dan perekonomian nasional, karena salah satu sumber pertumbuhan ekonomi adalah ekspor dan impor. Fluktuasi mata uang pada dasarnya merupakan fenomena yang wajar. Namun, fluktuasi yang sangat drastis akan menimbulkan persoalan bagi perekonomian domestik. Caputo \& Pedersen (2020) menemukan bahwa dalam sistem kurs yang mengambang, keberadaan fluktuasi kurs mempunyai pengaruh yang sangat dominan terhadap perekonomian dalam negeri. Untuk itu, Indonesia yang menganut sistem kurs mengambang tentu saja akan berhadapan dengan fluktuasi kurs dan akan merasakan pengaruhnya atas perekonomian domestik. Sementara itu, Viziniuc (2020) juga membuktikan bahwa fluktuasi kurs akan menimbulkan efek terhadap kesejahteraan masyarakat dalam negeri, dimana ada yang mengalami efek yang menguntungkan dan merugikan.

Selanjutnya dalam penelitian Manalo et al. (2015) dijelaskan bahwa ada beberapa sektor yang akan paling terpengaruh jika terjadi fluktuasi kurs. Sektor-sektor tersebut diantaranya pertambangan, manufaktur, jasa personal, kontruksi, dan jasa perusahaan. Studi Furlani et al. (2010) juga menyatakan bahwa fluktuasi kurs berpengaruh terhadap neraca perdagangan tingkat bunga dan inflasi.

Berdasarkan pada persoalan tersebut maka Bank Indonesia harus selalu berusaha untuk menjaga kestabilan nilai tukar rupiah melalui kebijakan intervensi di pasar valuta asing. Jika rupiah mengalami depresiasi maka Bank Indonesia akan membeli dolar dengan harapan agar kurs kembali stabil. Sebaliknya, jika rupiah mengalami apresiasi maka Bank Indonesia melepas cadangan dolar di pasar agar nilai tukar kembali ke posisi ideal.

Selain melakukan intervensi langsung, Bank Indonesia juga menggunakan tingkat bunga untuk melakukan pengendalian nilai tukar secara tidak langsung. Salah satu piranti kebijakan yang dapat dilakukan oleh Bank Indonesia adalah mengatur tingkat bunga. Jika terjadi depresiasi maka tingkat bunga dinaikkan agar tidak terjadi arus modal keluar; sebaliknya tingkat bunga lebih rendah pada saat terjadi apresiasi.

Pada Gambar 2 tercatat tingkat suku bunga pada bulan Januari 2018 berada pada angka $4,25 \%$ dan terus meningkat hingga bulan Juni 2018 berada pada angka 5,25\%. Meskipun tetap bertahan pada bulan Juli 2018, namun angka ini kembali meningkat pada bulan Agustus 2018 hingga mencapai $5,75 \%$ pada September 2018. Pada bulan November 2018 nilai suku bunga kembali meningkat mencapai $6,00 \%$ dan bertahan pada level angka yang sama hingga bulan Maret 2019.

Hubungan antara kurs dengan tingkat bunga ini bersifat dinamis mengikuti perkembangan pergerakan kurs. Namun, Indonesia relatif menerapkan tingkat bunga yang tinggi karena inflasi di Indonesia juga tinggi. Inflasi yang tinggi tersebut memaksa tingkat bunga tinggi agar tingkat bunga riil tetap positif. Secara teori, tingkat bunga tinggi berakibat pada tingkat keuntungan yang semakin kecil karena hanya investasi tertentu yang mampu menghasilkan penerimaan lebih tinggi dari tingkat bunga. Khusus untuk kasus Indonesia, meskipun tingkat bunga tinggi namun pertumbuhan masih tetap tinggi (Maryatmo, 2010).

Kondisi ini terjadi karena Indonesia mempunyai jumlah penduduk yang banyak, sehingga menjadi pasar yang sangat menjanjikan bagi pelaku bisnis. Selain itu, dengan tingkat pendapatan yang semakin tinggi sehingga memberikan pengaruh terhadap kegiatan konsumsi masyarakat dan akhirnya akan mempengaruhi kegiatan produksi yang berdampak pada pertumbuhan ekonomi. 


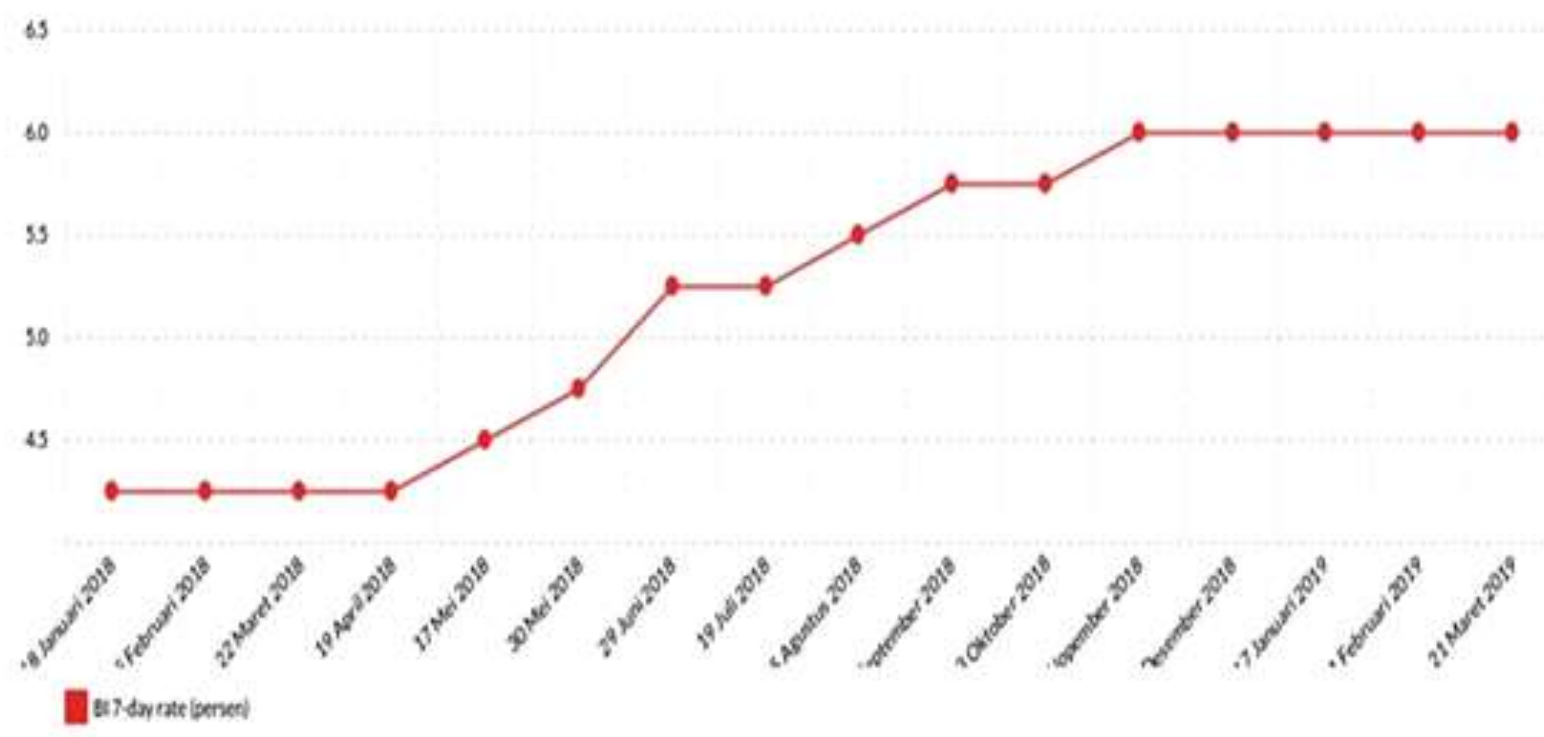

Gambar 2. Tren Suku Bunga Acuan Bank Indonesia Periode Januari 2018 - Maret 2019

Sumber: Bank Indonesia (2019).

Kebijakan pengaturan tingkat bunga tidak hanya berpengaruh terhadap stabilitas kurs tetapi lebih luas lagi juga berpengaruh terhadap kegiatan investasi dalam negeri (Syarifuddin, 2016). Stabilitas ekonomi dalam negeri dan stabilitas kurs harus dapat dicapai secara seimbang agar kedua sektor ini bisa berjalan bersama secara optimal. Kebijakan pengaturan tingkat bunga ini harus sangat dinamis dengan intens mempertimbangkan kestabilan ekonomi domestik sekaligus kestabilan perdagangan luar negeri melalui stabilitas kurs.

Berdasarkan pada pertimbangan itu, kajian dinamis respon kurs terhadap tingkat bunga ini sangat penting dilakukan. Hal ini terkait dengan kestabilan dua sektor ekonomi dalam negeri dan luar negeri.

\section{Kajian Teoritis}

Setidaknya terdapat empat sektor utama yang perlu berada dalam keseimbangan, yaitu pasar barang dan jasa, pasar tenaga kerja, pasar uang, dan pasar luar negeri. Antara suatu pasar dengan pasar lainnya mempunyai keterkaitan yang erat. Distorsi pada suatu pasar akan berakibat pada pasar lainnya.

Salah satu variabel yang berpengaruh terhadap pasar luar negeri adalah kurs. Stabilitas kurs sangat penting agar mampu mendorong pertumbuhan ekspor serta mengurangi impor sehingga tercipta net export yang positif. Jika terjadi depresiasi maka ekspor akan meningkat karena harga barang domestik di pasar internasional relatif lebih murah. Kondisi ini akan mendorong permintaan luar negeri yang lebih tinggi. Namun, kondisi saat ini Indonesia masih menggunakan komponen-komponen impor dalam memproduksi barang-barang yang diekspor ke luar negeri sehingga kondisi ini mengakibatkan terjadinya kenaikan harga barang impor yang berdampak juga pada kenaikan harga barang ekspor. Efeknya ini akan mengurangi impor, akibatnya ekspor juga mengalami penurunan.

Fluktuasi kurs ini juga berpengaruh terhadap pasar uang karena dengan bertambahnya pasokan dolar di dalam negeri menyebabkan mata uang domestik mengalami depresiasi, berakibat pada inflasi impor yang 
tinggi. Inflasi berpengaruh terhadap pasar uang sekaligus pasar barang dan jasa.

Inflasi yang tinggi akan mendorong Bank Indonesia melakukan intervensi dengan menaikkan tingkat bunga. Namun, kenaikan tingkat bunga berakibat pada kenaikan biaya produksi dan kondisi ini akan menaikkan harga jual. Saat harga jual naik maka permintaan akan turun, dimana penurunan permintaan yang besar berakibat kepada penurunan input, termasuk tenaga kerja. Dampaknya, sektor pasar tenaga kerja akan terganggu. Keterkaitan antara satu pasar dengan pasar yang lain sangat penting untuk diperhatikan dan dilakukan pengambilan kebijakan yang tepat.

Secara teori, ada tiga faktor yang menentukan perubahan nilai tukar ini, yaitu: (1) faktor fundamental perekonomian suatu negara; (2) faktor teknis antara permintaan dan penawaran uang; dan, (3) faktor sentimen pasar yang sangat sulit dikendalikan karena terkait dengan banyak faktor (Madura, 2009). Negara maju umumnya memiliki derajat fundamental ekonomi yang relatif bagus sehingga faktor ini tidak terlalu mengganggu nilai kurs. Berbeda dengan Indonesia yang masih berada pada posisi sebagai negara berkembang, dimana faktor fundamental masih menjadi variabel yang berpengaruh terhadap nilai kurs.

Faktor teknis menunjukkan bahwa kurs mengalami depresiasi di akhir tahun karena banyak perusahaan yang harus melakukan pembayaran hutang yang sudah jatuh tempo. Hutang luar negeri yang biasanya dalam mata uang dolar, akan menyebabkan permintaan atas dolar di akhir tahun selalu mengalami peningkatan. Ini berakibat pada depresiasi mata uang domestik. Faktor terakhir yang sangat sulit diawasi oleh pengambil kebijakan adalah kemungkinan munculnya efek-efek dari peristiwa politik tertentu yang berdampak pada fluktuasi mata uang.
Beberapa studi telah dilakukan untuk menganalisis pengaruh tingkat bunga atas kurs. Saraç \& Karagöz (2016) misalnya, menganalisis pengaruh tingkat bunga jangka pendek terhadap kurs di Turki. Hasil studi tersebut memperlihatkan bahwa tingkat bunga yang tinggi berakibat pada pelemahan nilai kurs. Akan tetapi, kurs tidak berpengaruh signifikan terhadap tingkat bunga. Hal ini bermakna bahwa tingkat bunga berpengaruh signifikan terhadap kurs hanya dalam jangka pendek di Turki.

Hasil yang relatif sama ditunjukkan dari studi yang dilakukan Inoue dan Rossi (2019) dengan memilih menggunakan tipe periode konvensional dan bukan konvensional. Hasil studi mereka menunjukkan bahwa penurunan tingkat bunga berakibat pada depresiasi kurs nominal baik pada periode konvensional maupun periode bukan konvensional. Namun dalam jangka panjang, efek tingkat bunga ini tergantung pada ekspektasi dari pelaku usaha terhadap tingkat bunga. Hasil lain dari studi mereka adalah bahwa tingkat bunga riil yang diharapkan memiliki peranan penting dalam transmisi kebijakan moneter.

Lueangwilai (2012) melakukan studi kebijakan moneter dan kurs di Thailand. Penelitian tersebut menggunakan model struktural dengan estimasi Bayesian. Hasil studi tersebut menunjukkan bahwa peran bank sentral sangat penting dalam menjaga stabilitas kurs di Thailand, dimana stabilitas kurs ini merupakan faktor yang sangat penting untuk mencapai stabilitas output.

Stabilitas kurs juga sangat berkaitan dengan pembangunan ekonomi melalui stabilitas output. Hasil studi dari Guzman et al. (2018) menemukan bahwa stabilitas kurs sangat penting bagi pembangunan ekonomi. Oleh karena itu, banyak bank sentral di berbagai negara yang melakukan intervensi terhadap stabilitas kurs. Disamping itu, dalam simulasi yang dilakukan oleh Egilsson (2020) 
memperlihatkan bahwa tingkat bunga sangat penting dalam menstabilkan kurs. Hasil simulasi tersebut mencakup beberapa psar, diantaranya pasar barang dan jasa, pasar tenaga kerja, pasar uang, pasar luar negeri sekaligus menjamin keuntungan maksimum bagi para pelaku usaha.

Sikarwar (2020) menyatakan bahwa intervensi bank sentral sangat berpengaruh terhadap fluktuasi kurs di negara dengan pasar emerging. Hasil studinya lebih khusus menunjukkan bahwa ada efek asimetris dari efek intervensi kurs oleh bank sentral terhadap penjualan valuta asing. Studi ini menjadi konfirmasi dari studi yang dilakukan oleh Li et al. (2013) yang meneliti efek lonjakan suku bunga terhadap fluktuasi kurs. Sementara itu, Andrieș et al. (2017) menemukan bahwa pada umumnya fluktuasi kurs selalu mendahului tingkat bunga, namun tindakan dari pihak otoritas keuangan yang melakukan intervensi terhadap fluktuasi kurs tersebut menyebabkan tingkat bunga mampu melakukan stabilisasi fluktuasi kurs tersebut.

Dimitriou et al. (2017) menyatakan tingkat kerawanan kurs akan berimplikasi terhadap manfaat diversifikasi portofolio karena risiko dari fluktuasi kurs relatif kecil. Mereka juga menemukan bahwa pengambil kebijakan moneter dinilai perlu melakukan koordinasi pengambilan kebijakan tingkat bunga sesuai dengan tingkat kerawanan perekonomian negara tersebut. Namun demikian, Demir (2014) mengingatkan bahwa respon terhadap pergerakan kurs secara kuantitatif relatif kecil. Lebih jauh, bank sentral umumnya membuat target pada fluktuasi kurs. Ini bermakna bahwa intervensi terhadap fluktuasi kurs hanya bersifat kebijakan tidak langsung.

Kabundi \& Mlachila (2019) mengingatkan bahwa intervensi bank sentral akan lebih efektif jika bank sentral memiliki kredibilitas yang sangat baik. Fluktuasi kurs lebih kecil di negara yang memiliki bank sentral dengan kredibilitas tinggi dibandingkan kredibilitas rendah. Hal ini sejalan dengan studi yang dilakukan oleh Chen (2007) yang menemukan bahwa tingkat bunga tinggi memiliki risiko fluktuasi kurs yang lebih tinggi juga. Tingkat bunga yang tinggi akan menjadi indikasi rendahnya kredibilitas bank sentral. Untuk itu perlu diingat bahwa kebijakan tingkat bunga ini bersifat jangka pendek (Sensoy \& Sobaci, 2014).

Granville \& Mallick (2010) menemukan situasi bahwa otoritas moneter gagal untuk menurunkan inflasi digit ganda sebagai upaya untuk mengurangi fluktuasi kurs. Ini menunjukkan bahwa saat inflasi tinggi, intervensi kurs menjadi kurang efektif. Aleem \& Lahiani (2014) menemukan bahwa kredibilitas otoritas moneter sangat berperan dalam menurunkan fluktuasi kurs.

\section{METODE PENELITIAN}

Salah satu variabel eksogen yang sangat berpengaruh terhadap perekonomian domestik adalah kurs. Kestabilan nilai kurs menjadi tugas yang sangat berat bagi para pengambil kebijakan moneter di negara-negara berkembang. Persoalan ini menjadi lebih berat lagi seperti misalnya di Indonesia yang menganut sistem perekonomian terbuka kecil (small open economy). Posisi Indonesia di dalam perdagangan internasional hanya sebagai pengikut (follower) dan bukan sebagai penentu perekonomian dunia.

Pergerakan kurs ini sangat dinamis dikarenakan fluktuasi perekonomian dunia berpengaruh terhadap kondisi kurs itu sendiri. Tidak ada kebijakan secara langsung yang dapat diambil pengambil kebijakan moneter terhadap kestabilan kurs ini. Kestabilan kurs hanya dapat diawasi melalui kebijakan tidak langsung, yaitu tingkat harga. Pergerakan tingkat bunga dan kurs bersifat dinamis; karena tingkat bunga disesuaikan dengan 
pergerakan kurs, sehingga perlu dilakukan estimasi dengan model dinamis.

\section{Metode Analisis}

Sebagaimana dijelaskan pada bagian sebelumnya bahwa model estimasi di dalam penelitian ini adalah model dinamis. Untuk itu, model tersebut dapat dijelaskan sebagai berikut:

$$
e r_{t}=\alpha_{0}+\beta_{1} \text { Rate }+\beta_{2} r_{t-1}+\varepsilon_{t}
$$

dimana $e r_{t}$ adalah kurs rupiah terhadap dolar Amerika (USD), serta Rate adalah tingkat bunga. Variabel kurs ditransformasikan ke dalam logaritma alamiah (ln), sedangkan tingkat bunga sudah dalam satuan persen. Estimasi dilakukan dengan data dari tahun 2002 hingga 2018 dengan total sampel sebanyak 17 tahun.

Persamaan (1) merupakan persamaan dinamis yang terdiri dari estimasi jangka pendek dan estimasi jangka panjang. Estimasi jangka pendek diwakili oleh koefisien $\beta_{1}$, sedangkan untuk estimasi jangka panjang diwakili oleh $\theta=\beta_{1}\left(1-\beta_{2}\right)$ (Asteriou \& Hall, 2011). Persamaan (1) juga menghasilkan koefisien elastisitas dari variabel bebas atas variabel tak bebas. Melalui persamaan (1) diharapkan mampu memberikan hasil yang lebih baik dan sesuai dengan tujuan penelitian ini, yaitu untuk menganalisis pengaruh jangka pendek dan jangka panjang (Gujarati \& Porter, 2009; Asteriou \& Hall, 2011).

\section{HASIL ANALISIS}

\section{Statistik Deskriptif Variabel}

Statistik deskriptif variabel bisa menggambarkan bagaimana distribusi data dan kemungkinan fluktuasi dalam data tersebut. Hasil statistik deskriptif variabel dalam penelitian ini ditunjukkan dalam Tabel 1.

Berdasarkan Tabel 1 terlihat tingkat bunga pernah mengalami tingkat tertinggi sebesar 39,07 persen dan ini terjadi pada saat krisis ekonomi yang melanda Indonesia. Akibat tingkat bunga yang sangat tinggi, maka distribusi tingkat bunga menjadi relatif tidak merata karena nilai terendah tingkat bunga sebesar adalah 5,95 persen. Rata-rata tingkat bunga selama periode penelitian sebesar 11,12 persen yang lebih besar dari median. Selain itu, distribusi data juga tidak normal karena nilai kurtosis sebesar 7,97 yang berarti distribusi data bersifat leptokurtik.

Selanjutnya, Tabel 1 menunjukkan distribusi atas variabel tingkat bunga miring ke kanan dan tidak terdistribusi secara normal karena distribusi normal dicapai jika nilai kurtosis sama dengan 3. Variasi tingkat bunga relatif tinggi sebesar 62,31 yang disebabkan adanya perbedaan yang sangat besar antara nilai terendah dan nilai tertinggi. Keadaan data tingkat bunga ini menunjukkan adanya fluktuasi yang relatif tinggi. Fluktuasi ini tidak terlepas dari naik dan turunnya kondisi perekonomian yang terjadi setiap waktu serta penyesuaian yang dilakukan untuk mencapai stabilitas berbagai variabel ekonomi termasuk nilai kurs.

Sementara itu, pergerakan data kurs relatif berbeda dengan tingkat bunga, di mana nilai tertinggi kurs pada periode penelitian sebesar Rp. 14.481 dan nilai ini tidak terlalu jauh dari nilai rata-rata sebesar Rp. 10.382,71. Namun, nilai terendah dari kurs relatif jauh dibandingkan dengan nilai rata-rata sebesar Rp. 7.085. Varians kurs relatif besar menandakan bahwa fluktuasi kurs relatif lebih besar dibandingkan dengan fluktuasi tingkat bunga. Bila pada variabel tingkat bunga distribusi data bersifat leptokurtik, maka distribusi kurs bersifat platikurtik yang menandakan bahwa distribusi kurs miring ke kiri karena nilai kurtosis sebesar -0,66; dan kedua variabel ini tidak terdistribusikan secara normal. Untuk lebih jelasnya, kondisi ini dapat dilihat pada Tabel 1. 
Tabel 1. Statistik Deskriptif Variabel

\begin{tabular}{lrr}
\hline \multirow{2}{*}{ Statistik } & \multicolumn{2}{c}{ Variabel } \\
\cline { 2 - 3 } & Rate & \multicolumn{1}{c}{ Kurs } \\
\hline Mean & 11,12 & $10.382,71$ \\
Median & 8,34 & $9.595,00$ \\
Standard Deviation & 7,89 & $2.095,66$ \\
Sample Variance & 62,31 & $4.391 .799,91$ \\
Kurtosis & 7,97 & $-0,66$ \\
Skewness & 2,72 & 0,68 \\
Range & 33,12 & $7.396,00$ \\
Minimum & 5,95 & $7.085,00$ \\
Maximum & 39,07 & $14.481,00$ \\
\hline
\end{tabular}

Sumber: Data Sekunder (diolah), 2019

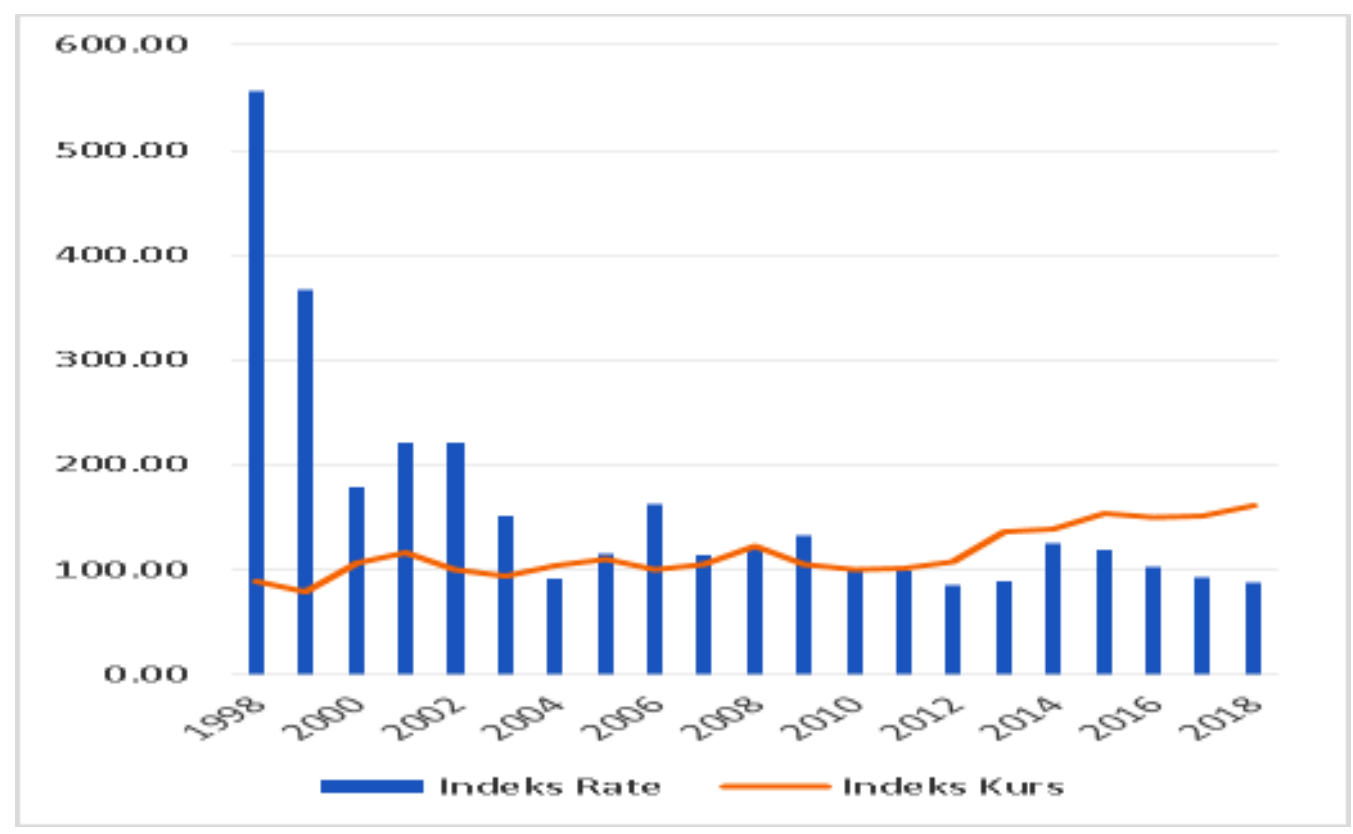

Gambar 3. Indeks Respons Kurs terhadap Tingkat Bunga, Periode 1998 - 2018

Sumber: Bank Indonesia (2019).

Agar respons kurs terhadap tingkat bunga ini terobservasi lebih jelas, maka Gambar 3 digunakan sebagai salah satu media. Nilai kurs dan tingkat bunga sudah ditransformasikan menjadi indeks karena adanya perbedaan satuan antara kedua variabel ini. Setelah ditransformasikan menjadi indeks maka penggabungan kedua variabel ini lebih baik dengan harapan mampu memberikan gambaran yang lebih optimal.
Tahun dasar untuk transformasi ini dipilih tahun 2010 karena pada tahun tersebut nilai kurs dan tingkat bunga relatif tidak jauh berbeda dengan statitistik deskriptif yang sudah dijelaskan pada bagian sebelumnya.

Tahun 1998 merupakan tahun krisis ekonomi yang dihadapi Indonesia ditandai dengan tingkat bunga yang sangat tinggi. Tingkat bunga yang tinggi ini merupakan salah satu kebijakan untuk menjaga agar kurs 
tidak mengalami depresiasi besar. Hal ini terlihat dari indeks kurs yang relatif tidak mengalami peningkatan drastis terlihat pada Gambar 3, indeks kurs justru tidak jauh berbeda dengan tahun dasar 2010. Tingkat bunga relatif bergerak perlahan pada awal krisis dan menjadi lebih rendah pada tahun 2004. Gambar 3 itu juga memperlihatkan bahwa indeks bunga justru lebih tinggi setelah tahun 2012 pada saat kurs hanya mengalami fluktuasi sedikit. Ini menggambarkan bahwa adanya kehati-hatian otoritas moneter dalam mengatur tingkat bunga sehingga stabilitas kurs bisa dicapai dan stabilitas sektor eksternal sekaligus lebih baik. Dengan adanya stabilitas dalam sektor eksternal diharapkan adanya kepastian berusaha bagi para eksportir sehingga proses produksi dalam negeri dan ekspor menjadi lebih terjamin dan kedua sektor bisa mencapai keseimbangan meskipun hanya dalam jangka pendek.

Estimasi model dinamis respons kurs terhadap tingkat bunga dilakukan dengan software Eviews 10. Hasil estimasi model disajikan di Tabel 2. Pada Tabel 2 tersebut memperlihatkan bahwa hasil estimasi model dinamis tersebut relatif bagus dikarenakan semua variabel signifikan secara teori dan signifikan secara statistik. Model estimasi juga mempunyai pengaruh yang signifikan secara bersama-sama. Namun, ada sedikit serial korelasi karena nilai Durbin-h sebesar 0,33 . Hal ini sangat rasional mengingat model yang digunakan adalah model autoregressive.

Secara keseluruhan, model ini dapat digunakan sebagai model analisis dalam penelitian. Pengujian asumsi linear klasik lainnya memperlihatkan bahwa tidak terdapat pelanggaran asumsi regresi linear klasik sebagaimana ditampilkan pada Tabel 3 yang memberikan konfirmasi bahwa model estimasi ini memenuhi syarat asumsi regresi linear klasik. Residual dalam model ini mempunyai distribusi normal dan tidak ada heteroskedastisitas dalam model tersebut. Berdasarkan pada hasil pengujian asumsi regresi linear klasik ini maka dinyatakan model ini sangat valid untuk digunakan dan tidak ada kemungkinan bias akibat estimasi.

Tabel 2. Respon Dinamis Kurs terhadap Bunga

\begin{tabular}{lcccc}
\hline \multicolumn{1}{c}{ Variabel } & Koef. & Std. Error & t-stat & Prob. \\
\hline Kostanta & $-1,469$ & 1,159 & 1,267 & 0,225 \\
Rate & $-0,257$ & 0,08 & $-3,219$ & $0,006^{*}$ \\
LnER(-1) & 0,901 & 0,122 & 7,352 & $0,000^{*}$ \\
Jangka Panjang & & & \\
Konstanta & $-14,838$ & & \\
$\theta$ Rate & $-2,595$ & & \\
R-Square & 0,831 & & \\
F-stat & 34,42 & & \\
Prob F-stat & $0,000 *$ & & \\
DW & 1,86 & & \\
Durbin-h & 0,33 & & \\
\hline
\end{tabular}

Ket: $*=$ Signifikan pada 0,05 .

Sumber: Data Sekunder (diolah), 2019 
Tabel 3. Pengujian Asumsi Klasik

\begin{tabular}{lcc}
\hline \multicolumn{1}{c}{ Uji Asumsi Klasik } & Chi-Square & Prob. \\
\hline Normalitas & 0,597 & 0,741 \\
Autokorelasi (2 lags) & 0,206 & 0,901 \\
Heteroskedastisitas & 0,351 & 0,838 \\
\hline
\end{tabular}

Sumber: Data Sekunder (diolah), 2019

Agar hasil estimasi dapat dianalisis dengan lebih tepat, maka hasil estimasi dari Tabel 2 dibagi menjadi dua bagian, yaitu estimasi jangka pendek dan estimasi jangka panjang. Hasil estimasi jangka pendek dinyatakan sebagai berikut:

$$
e r_{t}=-1,469-0,257 \text { Rate }+0,901 r_{t-1}
$$

Hasil estimasi jangka pendek ini signifikan secara teori karena koefisien bunga bertanda negatif yang menandakan bahwa kurs merespon kenaikan tingkat bunga menuju apresiasi, dengan asumsi ceteris paribus.

Selain itu, koefisien ini pun sangat signifikan secara statistik. Hasil ini memberi konfirmasi bahwa tingkat bunga domestik sangat penting untuk mencapai stabilitas kurs meskipun tingkat bunga merupakan piranti tidak langsung terhadap kurs. Kenaikan tingkat bunga akan diikuti oleh peningkatan arus modal luar untuk masuk ke Indonesia sehingga pasokan mata uang asing terutama dolar Amerika mengalami kenaikan dalam jangka pendek. Kenaikan pasokan dolar Amerika berpengaruh terhadap penurunan nilai dolar terhadap rupiah, sehingga rupiah mengalami apresiasi. Sebaliknya, jika bunga mengalami penurunan maka mata uang asing akan keluar dari Indonesia, sehingga terjadi outflow. Kondisi outflow akan berakibat pada penurunan pasokan dolar di dalam pasar domestik. Hal ini akan berakibat pada peningkatan nilai mata uang dolar terhadap rupiah yang berarti terjadi depresiasi.

Respon kurs terhadap tingkat bunga ini menjadi indikasi yang baik karena otoritas moneter masih bisa menggunakan tingkat bunga untuk menstabilkan fluktuasi kurs. Hal ini bisa terjadi karena selisih tingkat bunga domestik terhadap tingkat bunga luar negeri yang sangat besar menjadi motivasi tersendiri bagi pemilik modal untuk menyimpan uang mereka di Indonesia.

Selanjutnya, untuk estimasi jangka panjang diperoleh:

$$
e r_{t}=-14,838-2,595 \text { Rate }
$$

Hasil ini memperlihatkan nilai koefisien jangka panjang adalah relatif lebih besar dibandingkan dengan nilai koefisien jangka pendek. Ini membuktikan bahwa kepercayaan modal asing terhadap kebijakan moneter dalam bentuk tingkat bunga memiliki respon yang lebih besar. Kondisi ini menjadi indikasi bahwa kepercayaan investor asing di pasar uang Indonesia dalam jangka panjang sangat besar. Hal tersebut tidak terlepas dari makin meningkatnya pertumbuhan ekonomi dan kondisi politik nasional yang stabil hingga meningkatkan kepercayaan para pemodal terhadap kebijakan moneter di Indonesia.

Respons kurs dalam jangka panjang lebih elastik dibandingkan jangka pendek. Ini menjadi konfirmasi bahwa fundamental ekonomi Indonesia mempunyai pengaruh yang jauh lebih besar. Jika terjadi gejolak ekonomi maka akan terjadi arus keluar (outflow) dari Indonesia dalam jumlah yang sangat besar. Kondisi ini akan berdampak pada pasar domestik lainnya seperti pasar barang dan jasa, pasar tenaga kerja, dan pasar uang. Berdasarkan pada hasil ini, otoritas 
moneter sebaiknya selalu berhati-hati dalam menentukan tingkat bunga karena akan mendapat respons yang sangat besar dalam peride jangka panjang dan bersifat signifikan dalam jangka pendek.

\section{Pembahasan}

Penguatan fundamental ekonomi harus menjadi agenda utama dalam pembangunan ekonomi Indonesia. Fundamental ekonomi yang kuat dengan didukung oleh ketimpangan pembangunan yang kecil menjadi salah satu faktor penting yang diharapkan oleh investor dari luar Indonesia.

Hasil penelitian ini memiliki kesamaan dan perbedaan dengan penelitian yang pernah dilakukan sebelumnya. Pada penelitian ini menunjukkan hasil bahwa tingkat bunga signifikan baik dalam jangka pendek maupun jangka panjang. Koefisien elastisitas jangka pendek lebih kecil dibandingkan dengan jangka panjang. Hasil ini sama dengan studi yang dilakukan oleh Saraç \& Karagöz (2016) untuk jangka pendek, tetapi berbeda untuk kondisi dalam jangka panjang. Hal yang relatif sama dengan hasil penelitian dari Inoue \& Rossi (2019) serta hasil studi Lueangwilai (2012) untuk kasus di Thailand.

Selanjutnya, hasil studi ini mendukung kajian yang dilakukan oleh Guzman et al. (2018) yang memperlihatkan peran bank sentral dalam melakukan stabilisasi fluktuasi kurs melalui piranti tingkat bunga. Ini menjadi bukti dari simulasi estimasi yang dilakukan oleh Egilsson (2020), dimana simulasi itu memperlihatkan bahwa stabilitas kurs sangat penting untuk mendapatkan keuntungan maksimum di semua pasar baik pasar domestik maupun luar negeri.

Kajian Caputo \& Pedersen (2020) menemukan sistem kurs yang mengambang mempunyai kemungkinan fluktuasi yang lebih besar. Hal ini dialami Indonesia karena Indonesia juga menggunakan sistem kurs yang mengambang. Fluktuasi kurs ini mempunyai pengaruh yang signifikan atas beberapa sektor jika kurs mengalami fluktuasi. Hal ini sesuai dengan kajian yang dilakukan Viziniuc (2020) yang menyatakan bahwa sektor pertambangan, manufaktur, dan jasa perusahaan merupakan sektor yang paling rentan akibat fluktuasi kurs ini.

Sebagai suatu pasar ekonomi yang sangat potensial, fluktuasi kurs di Indonesia perlu dikendalikan dengan kebijakan moneter yang sesuai dengan hasil studi ini, meskipun kebijakan moneter merupakan kebijakan tidak langsung namun masih sangat efektif dalam mengendalikan fluktuasi kurs. Intervensi otoritas monoter ini sangat penting sesuai dengan hasil studi yang dilakukan oleh Sikarwar (2020). Dengan demikian, hasil studi ini sangat sejalan dengan hasil studi yang dilakukan oleh Sikarwar tersebut.

\section{SIMPULAN}

Berdasarkan hasil estimasi dan analisis yang diperoleh dalam penelitian ini, ada beberapa kesimpulan yang dapat diambil. Pertama, kurs sangat responsif terhadap tingkat bunga di Indonesia. Kedua, pengaruh tingkat bunga terhadap kurs bernilai negatif dan sangat signifikan baik jangka pendek maupun jangka panjang. Ketiga, pengaruh tingkat bunga terhadap kurs dalam jangka panjang lebih besar dari pada jangka pendek.

Rekomendasi dari penelitian ini adalah sebagai berikut. Pertama, otoritas moneter dapat menggunakan tingkat bunga untuk menstabilkan fluktuasi kurs. Kedua, otoritas moneter perlu sangat berhati-hati dalam menentukan tingkat bunga agar semua pasar dapat mencapai keseimbangan optimal. Ketiga, agenda pembangunan harus dilakukan untuk memperkuat fundamental ekonomi Indonesia sekaligus sebagai upaya untuk memperkecil ketimpangan pembangunan antardaerah. 
Mengingat Indonesia yang menganut sistem kurs yang mengambang dengan efek fluktuasi kurs lebih besar dan beberapa sektor yang akan menerima pengaruh lebih besar, maka pemerintah dan otoritas monoter harus secara terintegrasi dan berkelanjutan dalam melakukan peningkatan fundamental dan harus didukung oleh kebijakan moneter yang baik. Dengan melakukan kebijakan yang tepat tersebut maka fluktuasi kurs dapat dikurangi serta kemungkinan timbulnya efek lebih besar terhadap sektor utama dalam ekonomi dapat dikurangi.

\section{REFERENSI}

Aleem, A., \& Lahiani, A. (2014). Monetary policy credibility and exchange rate pass-through: Some evidence from emerging countries. Economic Modelling, 43, 21-29. doi: 10.1016/ j.econmod.2014.06.020.

Andrieș, A. M., Căpraru, B., Ihnatov, I., \& Tiwari, A. K. (2017). The relationship between exchange rates and interest rates in a small open emerging economy: The case of Romania. Economic Modelling, 67, 261-274. doi: 10.1016/j.econmod.2016.12.025.

Anonim. (2019). Nilai rupiah terhadap dolar. Retrieved from https://www.seputar forex.com/, tanggal 30 November 2019.

Asteriou, D., \& Hall, S. G. (2011). Applied econometrics $\quad\left(2^{\text {nd }} \quad\right.$ Ed.). Palgrave Macmilan.

Caputo, R., \& Pedersen, M. (2020). The changing nature of the real exchange rate: The role of Central Bank preferences. Economic Modelling, 90, 445-464. doi: 10.1016/j.econmod.2019. 11.029 .

Chen, S-S. (2007). A note on interest rate defense policy and exchange rate volatility. Economic Modelling, 24(5), 768-777. doi: 10.1016/j.econmod.2007. 02.002 .
Demir, I. (2014). Monetary policy responses to the exchange rate: Empirical evidence from the ECB. Economic Modelling, 39, 63-70. doi: 10.1016/j.econmod.2014. 02.024 .

Dimitriou, D., Kenourgios, D., \& Simos, T. (2017). Financial crises, exchange rate linkages and undercovered interest parity: Evidence from G7 markets. Economic Modelling, 66, 112-120. doi: 10.1016/j.econmod.2017.06.003.

Egilsson, J. H. (2020). How raising interest rates can use inflation and currency depreciation. Journal of Applied Economics, 23(1), 450-468. doi: 10.1080/15140326.2020.1795526.

Furlani, L. G. C., Portugal, M. S., \& Laurini, M. P. (2010). Exchange rate movements and monetary policy in Brazil: Econometric and simulation evidence. Economic Modelling, 27(1), 284-295. doi: 10.1016/j.econmod.2009.09.008.

Granville, B., \& Mallick, S. (2010). Monetary policy In Russia: Identifying exchange rate shocks. Economic Modelling, 27(1), 432-444. doi: 10.1016/j.econmod.2009. 10.010 .

Gujarati, D., \& Porter. D. (2009). Basic econometrics $\left(5^{\text {th }} \mathrm{Ed}\right)$. McGraw-Hill.

Guzman, M., Ocampo, J. A., \& Stiglitz, J. E. (2018). Real exchange rate policies for economic development. World Development, 110, 51-62. doi: 10.1016/ j.worlddev.2018.05.017.

Inoue, A., \& Rossi, B. (2019). The effect of conventional and unconventional monetary policy on exchange rates. Journal of International Economics, 118, 419-447. doi: 10.1016/j.jinteco. 2019.01.015.

Kabundi, A., \& Mlachila, M. (2019). The role of monetary policy credibility in explaining the decline in exchage rate pass-through in South Africa. Economic Modelling, 79, 173-185. doi: 10.1016/ j.econmod.2018.10.010.

Li, X-P., Feng, Y., Wu, C-F., \& Xu, W-D. (2013). Response of the term structure of forward exchange rate to jump in the 
interest rate. Economic Modelling, 30, 863-874. doi: 10.1016/j.econmod.2012. 11.005

Lueangwilai, K. (2012). Monetary policy rules and exchange rate uncertainty: A structural investigation in Thailand. Procedia Economics and Finance, 2, 325-334. doi: 10.1016/S2212-5671(12) 00094-9.

Madura, J. (2009). Financial markets and institutions $\left(9^{\text {th }}\right.$ Ed). McGraw-Hill.

Manalo, J., Perera, D., \& Rees, D. M. (2015). Exchange rate movements and the Australian economy. Economic Modelling, 47, 53-62. doi: 10.1016/ j.econmod.2015.02.013.

Maryatmo, R. (2010). Pengaruh jangka pendek dan jangka panjang perubahan suku bunga dan kurs rupiah terhadap harga saham: Studi empiris di Indonesia (2000:1-2010:4). Jurnal Ekonomi dan Kebijakan, 3(1), 1-11. doi: 10.15294/ jejak.v3i1.4660.

Saraç, T. B, \& Karagöz, K. (2016). Impact of short-run interest rate on exchange rate: The case of Turkey. Procedia Economics and Finance, 38, 195-202. doi: 10.1016/S2212-5671(16)30190-3.
Sensoy, A., \& Sobaci, C. (2014). Effects of volatility shocks on the dynamic linkages between exchange rate, interest rate and the stock market: The case of Turkey. Economic Modelling, 43, 448457. doi: 10.1016/j.econmod.2014.09. 005.

Sikarwar, E. (2020). Forex interventions and exchange rate exposure: Evidence from emerging market firms. Economic Modelling, 93, 69-81. doi: 10.1016/ j.econmod.2020.07.010.

Syarifuddin, F. (2016). Konsep, dinamika dan respon kebijakan nilai tukar di Indonesia. BI Institute.

Todaro, M. P. (2000). Economic development $\left(7^{\text {th }}\right.$ Ed.), International Edition. AddisonWesley.

Viziniuc, M. (2021). Winners and losers of Central Bank foreign exchange interventions. Economic Modelling, 94, 748-767 doi: 10.1016/j.econmod.2020. 02.016 . 